\title{
INFLUENCE OF THE QUALITY OF MODELS MADE BY ADDITIVE Technologies on THe Quality OF Castings CaST bY INVESTMENT CASTING
}

\author{
David Bricín*, Filip Votava, Dana Kubátová \& Antonín Kř̌́ž
}
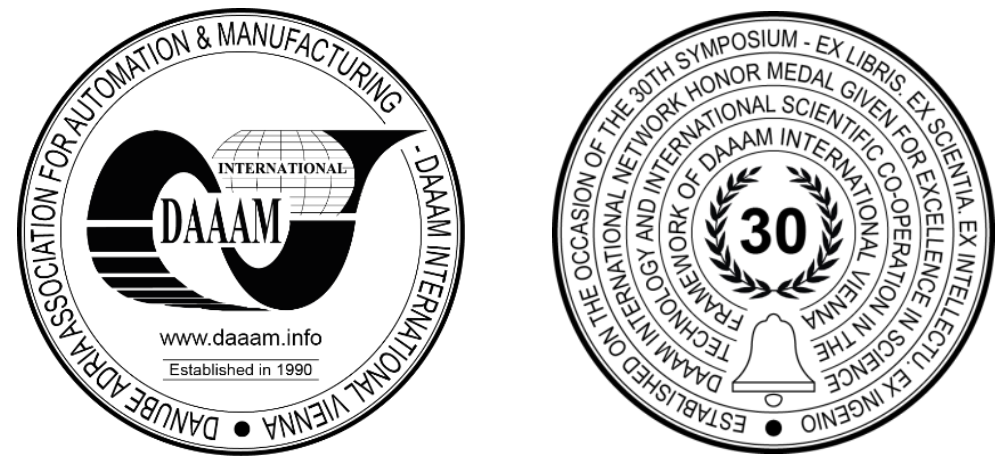

This Publication has to be referred as: Bricin, D[avid]; Votava, F[ilip]; Kubatova, D[ana] \& Kriz, A[ntonin] (2020). Influence of the Quality of Models Made by Additive Technologies on the Quality of Castings Cast by Investment Casting, Proceedings of the 31st DAAAM International Symposium, pp.0467-0476, B. Katalinic (Ed.), Published by DAAAM International, ISBN 978-3-902734-29-7, ISSN 1726-9679, Vienna, Austria

DOI: $10.2507 / 31$ st.daaam.proceedings.066

\begin{abstract}
The article deals with the use of additive technologies (AM) to produce a fusible model for a casting. AM technologies SLA, FDM, or PolyJet have been used to create models of castings of musical instrument keys from various polymeric materials. The roughness profiles of the models were determined and their combustibility during the mould firing process was tested. After these tests, moulds were made from the models, the moulds were fired, and the casting was made using the selected metal alloy. The final quality of the castings was then evaluated by metallographic analysis using SM, SEM, and X-ray techniques. Evaluation of the results revealed for example that the laboriousness of machining the casting increases with the proportion of ash which arises during the firing process of the mould and is further dependent on the surface quality of the model.
\end{abstract}

Keywords: Porosity; Surface Roughness; Investment Casting; AM technologies.

\section{Introduction}

The technology of casting using a fusible model is one of the oldest known technologies for the production of weapons and works of art. It was used for this purpose several millennia ago [1], [2]. Since then, the technology has undergone a number of innovations and it is currently used mainly for producing components with complex shapes, mostly in serial and mass production. Among the products that are currently produced with this technology are, for example, keys for musical instruments, see Fig. 1. The investment casting method is used for these products because it allows the production of parts with high surface quality within narrow dimensional tolerances. As is known with this technology, it is possible to obtain the final shape of a machine part without the need to further modify or machine it. In some cases, however, the functional surfaces or visible surfaces of the casting are modified, for example by grinding or depositing various layers, which is the case for musical instrument keys. From a technological and time point of view, this is a demanding production process consisting of a series of steps. The casting is created using various technologies starting with the production of the parent model and mould, through the creation of wax models and their assemblies, to the creation of the mould for casting, its firing, and final pouring of the alloy from which the casting is to be made. 


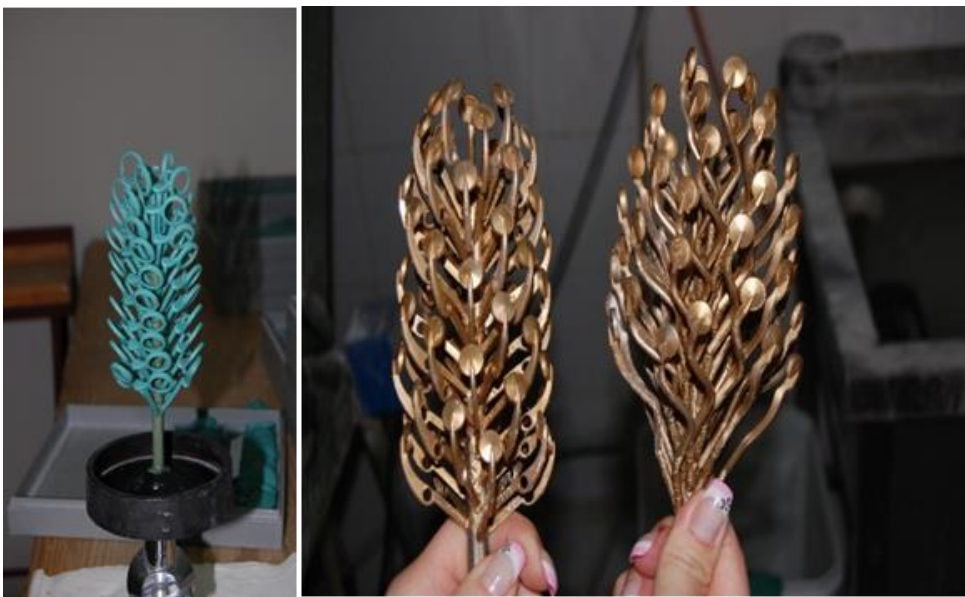

Fig. 1. Set of key castings for musical instruments. On the left, an example of a set of wax models, on the right an example of castings after removing the moulding compound [3]

One ways to reduce the complexity of the production of keys castings and thus to shorten the time required for their completion is by using additive technology. This technology, as can be seen from Figure 2, can theoretically be implemented at various stages of casting production processed by IC technology, from production of the parent model, through the production of wax models, production of entire moulds for casting, to complete replacement of precision casting technology with a suitable additive technology.

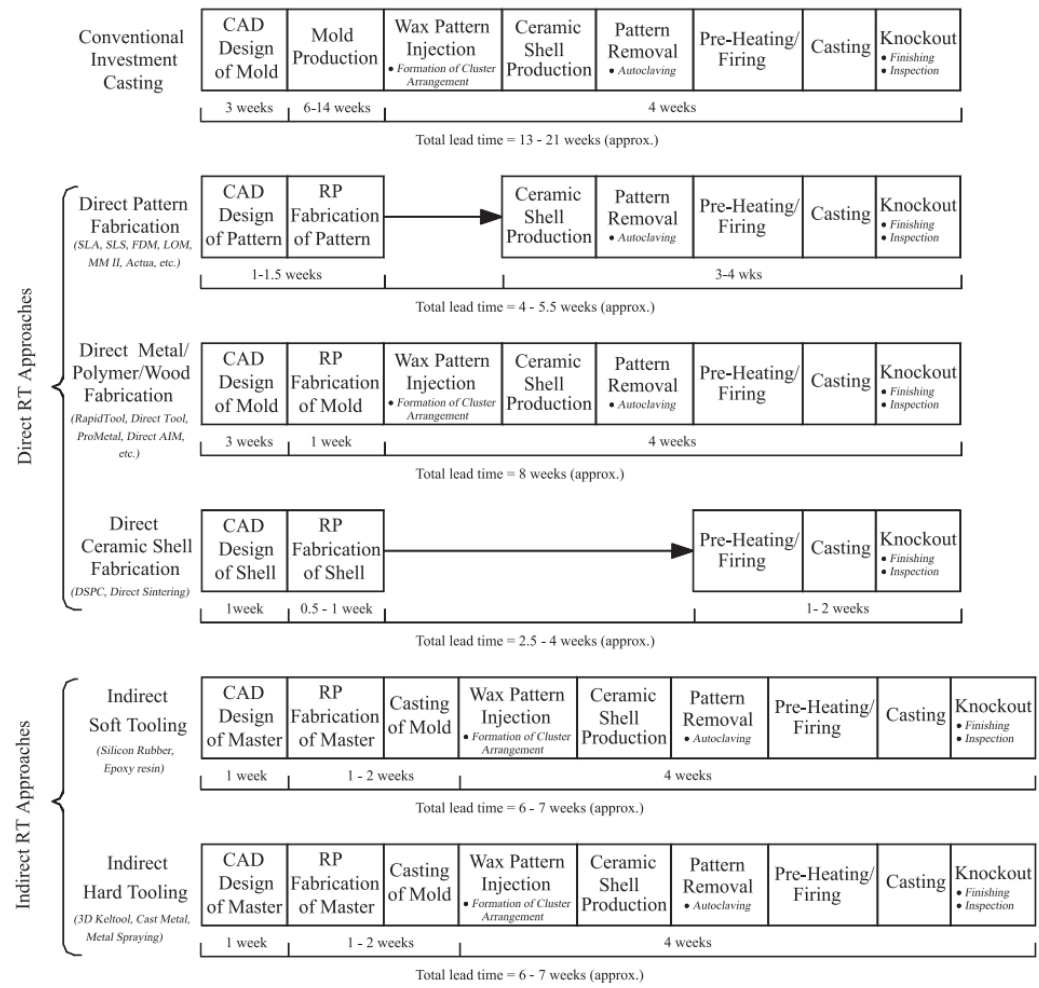

Fig. 2. Comparison of conventional processes of casting production using a fusible model with processes that implement AM technologies [4]

In this case study, we focused on evaluating the quality of castings when AM technologies are used in the production of wax (polymer) models to create a cavity in a mould for casting a metal alloy. The reason for using AM technologies in the production of wax models is related to the good availability of these technologies and the large number of available polymeric materials that can be processed by these technologies. The aim of the study was to compare the surface quality of models created from different materials on different AM devices and then also the surface quality of the castings created using these models. The roughness and topography of the surfaces of the models and castings were measured. The polymer materials were then compared in terms of the amount of fumes that are generated during their combustion during the firing of the moulding material. 
The control of the proportion of these products and the non-combustible parts of the material was compared with the values found for wax, which is commonly used for the production of such models. The surface quality of castings created after moulding and firing of moulds with models using AM equipment was finally compared with the surface quality of castings of the same type of keys for wind instruments produced by the conventional process using investment casting technology. The casting model of the key, which was also used as a basis for the production of the polymer models is shown below, see Fig. 3. By comparing all the data, it was possible to determine the ability of AM technologies and materials to replace a conventional wax model.

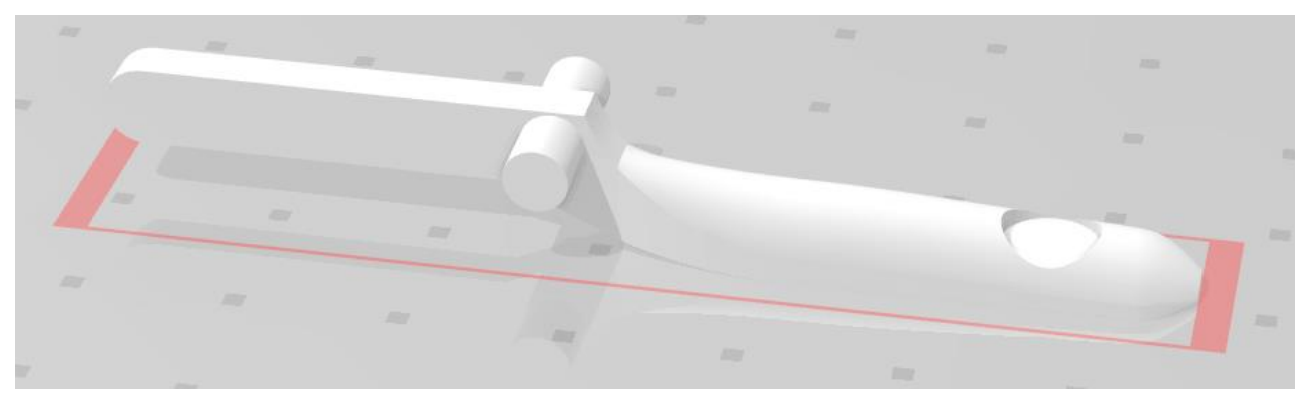

Fig. 3. Model of a key for a musical instrument used for the production of a wax model

\section{Materials and parameters used in the experiment}

\subsection{Materials and AM technology used}

Polymer models were created using four different AM production technologies, see Table 1. Each of these technologies, depending on the type of printer used, allows the model to be produced with different accuracies and surface qualities. The final properties of the polymer models thus depend on the parameters used for their production, but also on the processed material, its chemical composition and form, i.e. whether it is a resin, powder, or string.

\begin{tabular}{|c|c|c|c|c|c|c|c|}
\hline $\begin{array}{c}\text { Printing } \\
\text { Technology }\end{array}$ & $\begin{array}{c}\text { Printer } \\
\text { Type }\end{array}$ & Material & $\begin{array}{c}\text { Print } \\
\text { Temperature } \\
{ }_{\left({ }^{0} \mathrm{C}\right)}\end{array}$ & $\begin{array}{c}\text { Plate } \\
\text { Temperature } \\
{ }_{\left({ }^{\circ} \mathrm{C}\right)}\end{array}$ & $\begin{array}{c}\text { Layer } \\
\text { Thickness } \\
(\mathbf{m m})\end{array}$ & $\begin{array}{l}\text { Material } \\
\text { Form }\end{array}$ & $\begin{array}{c}\text { Filling } \\
\text { the } \\
\text { Model } \\
(\%)\end{array}$ \\
\hline \multirow{4}{*}{ FDM } & \multirow{2}{*}{$\begin{array}{l}\text { Geetech } \\
\text { A10M }\end{array}$} & PLA & 210 & 42 & 0.1 & String & 15 \\
\hline & & Mouldlay & 180 & 40 & 0.1 & String & 15 \\
\hline & $\begin{array}{c}\text { Original } \\
\text { Prusa i3 } \\
\text { MK3S }\end{array}$ & PLA & 210 & 42 & $0.1 / 0.05$ & String & 15 \\
\hline & Ultimaker S5 & PVA & 190 & 40 & & String & 15 \\
\hline SLA & $\begin{array}{c}\text { Original } \\
\text { Prusa SL1 }\end{array}$ & $\begin{array}{c}\text { Castable } \\
\text { Wax }\end{array}$ & - & - & & Resin & 100 \\
\hline MJM & $\begin{array}{c}\text { ProJet } 3510 \\
\text { HD }\end{array}$ & $\begin{array}{c}\text { VisiJet M3 } \\
\text { Crystal+ } \\
\text { VisiJet S300 }\end{array}$ & - & - & & Resin & 100 \\
\hline MJF & $\begin{array}{c}\text { HP Jet } \\
\text { Fusion } 4200\end{array}$ & $\begin{array}{l}\text { HP 3D High } \\
\text { Reusability } \\
\text { PA } 12\end{array}$ & - & - & 0.08 & Powder & 100 \\
\hline
\end{tabular}

Table 1. Parameters for processing polymeric materials, their form, types of printer, and processing technologies

\subsection{Analysis of topography and surface structure of models and castings}

The topography of the surface and the surface roughness was analysed for the created polymer models and subsequently also for castings. The roughness was measured on a Hommel-Etamic T8000 roughness tester, with a $2 \mu \mathrm{m}$ diamond tip at an apex angle of $90^{\circ}$. Four measurements were performed on each sample: two longitudinal measurements in the sample axis $(\mathrm{P})$ and two measurements perpendicular to them $(\mathrm{K})$, see the measurement diagram in Figure 4. Two measurements in each direction were performed due to subsequent evaluation according to the ČSN EN ISO 4287: 1999 standard [5]. The evaluation was based on a shortened elevation. The shortening of the basic profile was performed due to the shape of the damper model, where the full length of the basic profile would exceed the range of the meter $(+/-400$ $\mu \mathrm{m})$. 
In the case of longitudinal measurement $(\mathrm{P})$, the measured length was $4.8 \mathrm{~mm}$ with a feed rate of $0.5 \mathrm{~mm} / \mathrm{s}$, and a Gaussian linear filter ČSN EN ISO 16610-21 was used [6] (before ČSN EN ISO 11 562) with a cut-off value of 2.5 mm. In the case of perpendicular measurement $(\mathrm{K})$, the measured length was $3.2 \mathrm{~mm}$, the feed rate $0.5 \mathrm{~mm} / \mathrm{s}$. The filter used was the same as for the longitudinal $(\mathrm{P})$ measurement, with a difference in the cut-off value of $0.8 \mathrm{~mm}$.

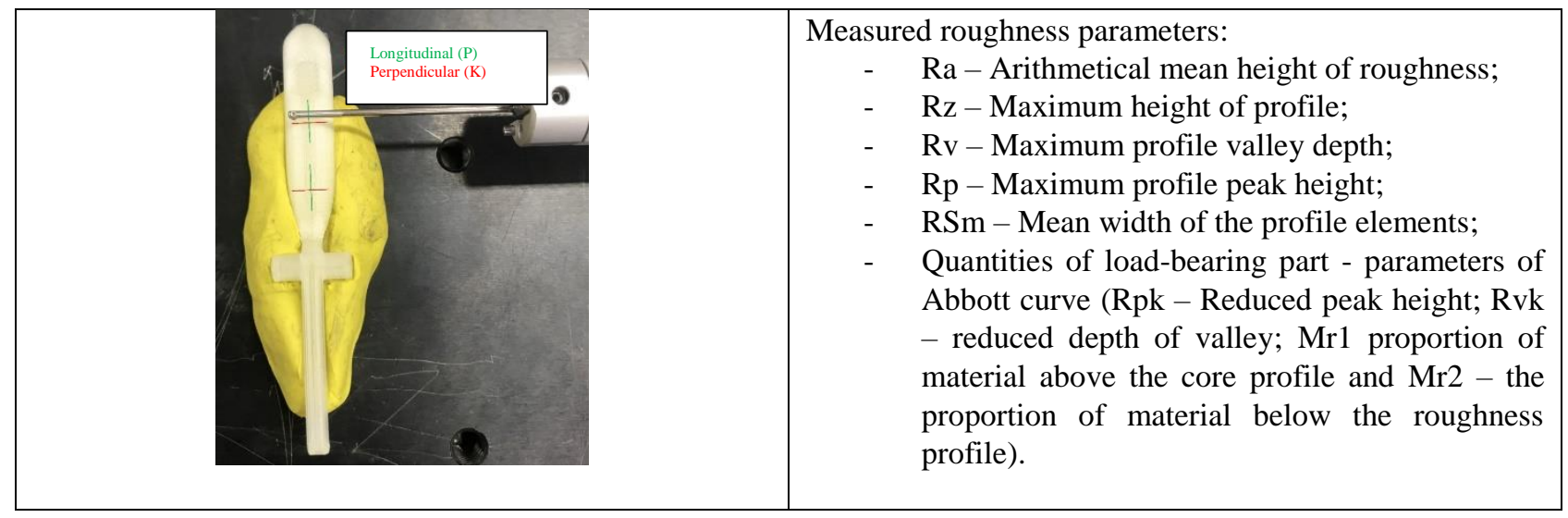

Fig. 4. The places in which Roughness measurements were taken

Surface topography was measured on an IFM G4 optical scanning microscope in a 10x objective configuration with a vertical resolution of $2.0249 \mu \mathrm{m}$ and a lateral resolution of $1.9012 \mu \mathrm{m}$. The surface was scanned on the back of the keys model (in the same place as one of the longitudinal measurements on the roughness meter was made). The result of the measurement is then a colour image showing the recorded height differences of the profile.

\subsection{Firing parameters of polymeric materials and moulds for casting}

The proportion of ash formed during the firing of the mould was determined for the processed polymeric materials. This analysis consisted of taking the material, weighing the sample and the ceramic crucible in which the material was placed, using precision laboratory balances Radwag AS $220 / \mathrm{C} / 2$, firing the material at $720^{\circ} \mathrm{C}$ and finally weighing the ceramic crucibles after the firing process. The value of ash found in the polymer materials used to make the model on AM equipment was then compared with the value found in the wax material Flexible Blue, which is currently used in the production of models using investment casting technology.

In addition to the above analyses, some of the polymer models were formed in Gold star XL gypsum. After forming into the moulds, the moulds were fired. This firing consisted of stepwise heating of the mould, see Fig. 5. The firing of the mould was followed by the casting of the tin alloy. The aim of this analysis was to determine the difference between the final quality of the casting obtained using different materials and AM technologies with the quality of the casting that was made in a conventional manner. Visual inspection of surface defects and their evaluation according to the ČSN 42 1240 standard was performed on the castings [7].

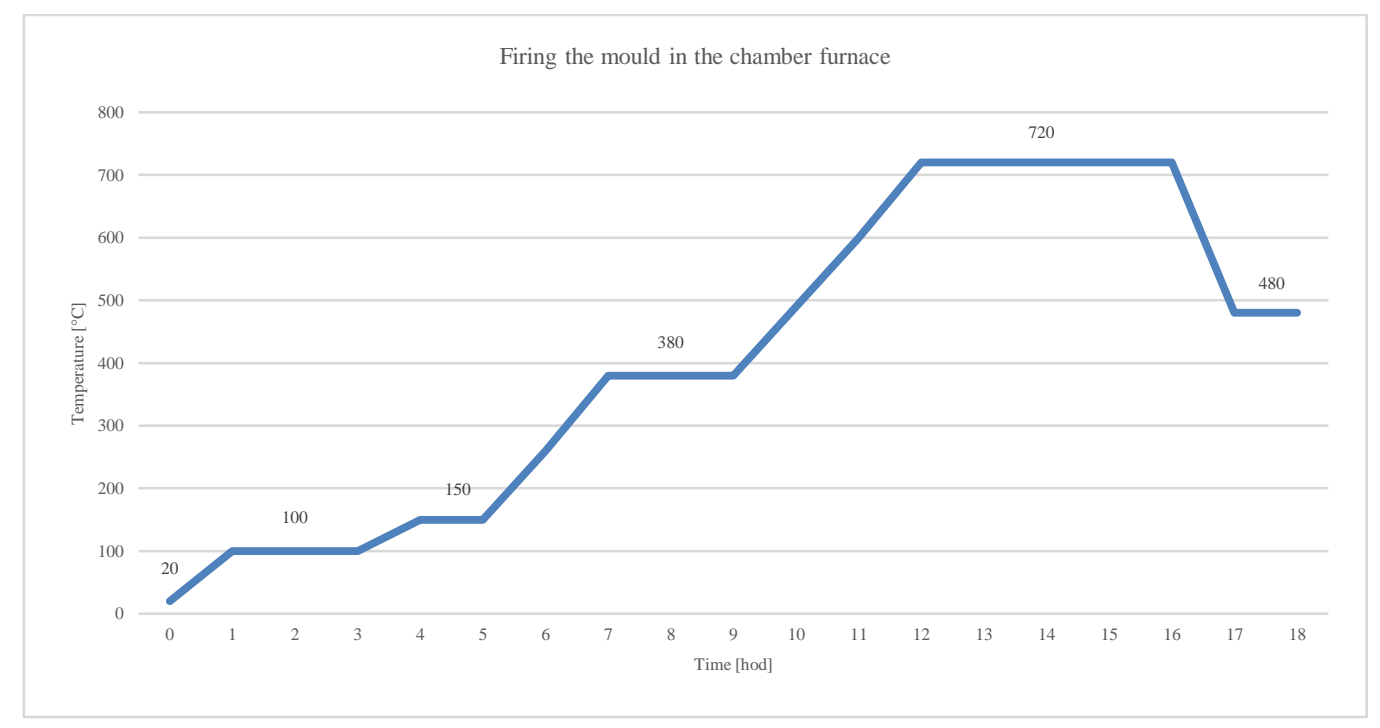

Fig. 5. Temperature v time graph for firing moulds before casting with the tin alloy 


\section{Results and discussion}

\subsection{Ash content}

The final surface quality of the castings depends, among other things, on the proportion of non-combustible parts of the polymeric material used to produce the fusible model. The proportion of this ash should be as low as possible because it remains trapped in the cavity of the mould. Here, it interacts with the molten cast metal and causes surface and subsurface defects in its structure. Below, see Fig. 6, the results of the analysis of the combustibility of polymeric materials processed using various additive techniques are shown.
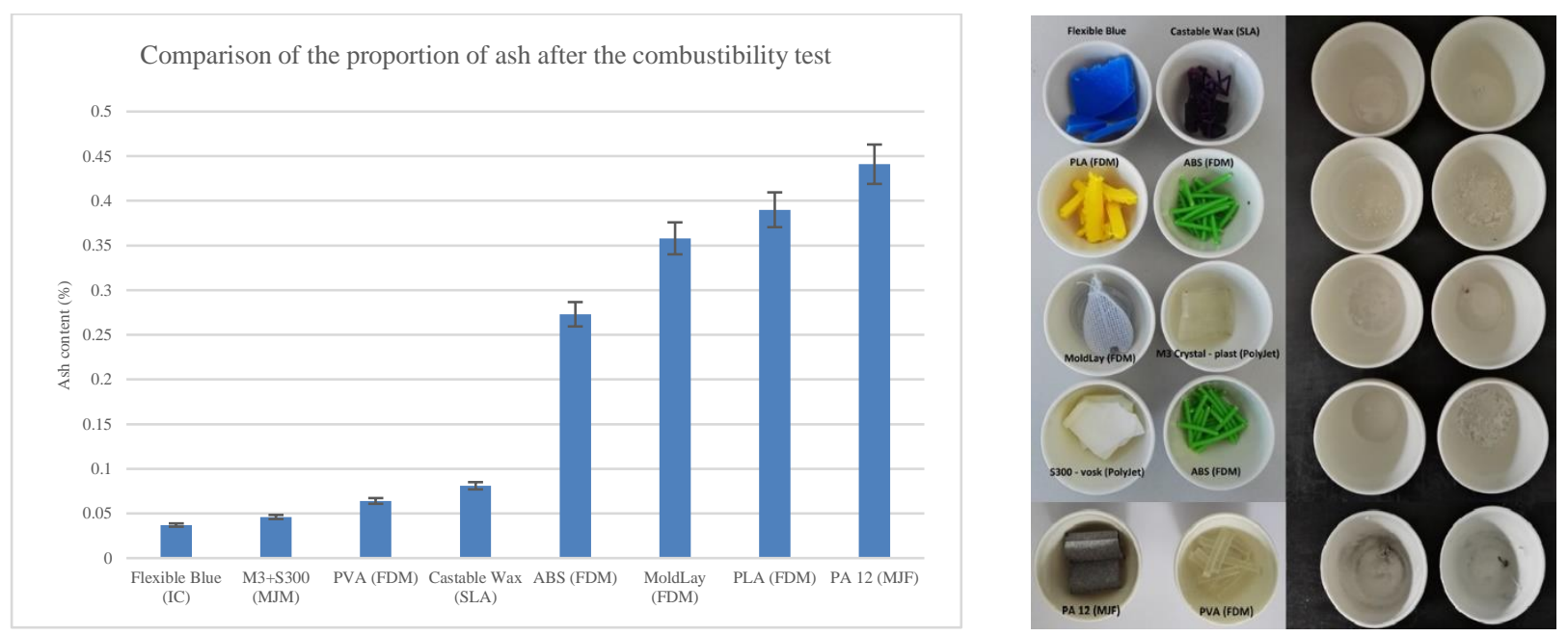

Fig. 6. Comparison of the share of ash in the processed materials. The right part of the figure shows the polymeric materials before and the non-combustible proportion of ashes after the combustibility test.

The graph in this figure (Fig. 6) shows that all the polymeric materials used to make the fusible model using AM techniques, had a higher ash content of up to $1100 \%$ in the case of PA12 compared to the commonly used Flexible Blue wax. A higher proportion of ash is associated with a higher resistance of these polymers to their thermal degradation. The intensity of this degradation then depends on the cohesiveness of the bonds that act between the polymer macromolecules. Disruption of these bonds (thermal degradation) can take place in various ways, primarily by depolymerization, accidental cleavage of macromolecule chains or elimination of side groups of these chains [8]. The cohesiveness of the bonds that hold these macromolecules together is affected by their chemical structure, i.e., their elemental composition and the types of bonds that are used here. For example, the more cross-links in the polymeric structure between the molecules, or the more ordered the structure, i.e. the higher the proportion of crystalline phase, the higher the strength and temperature resistance of the polymer. This can then lead to a higher proportion of non-combustible products when firing the foundry mould.

These non-combustible products can have a high adhesion to the mould surface. In the experiment, the noncombustible components of polymers PA12 and ABS showed the highest adhesion, i.e. resistance to removal. Their high adhesion and volume on the surface of the mould cavity could then lead to an increase in the proportion of surface defects in the casting. In addition, chemical reactions may occur between the resulting flue gas and the mould cavity interface, causing the mould interface to be disrupted. This would again lead to a deterioration of the surface quality of the casting and this would lead to an increase in the laboriousness of its further processing.

\subsection{Topography and surface roughness of samples}

The final surface quality of the casting further depends on the processing quality of the wax model. For the conventional production of a wax model, techniques of injecting the polymer into the parent mould are often used. The final quality of the wax model in terms of its surface quality and internal porosity depends on the injection temperature used, the injection pressure used, the holding time at the injection temperature and the processing quality of the mother mould for its production [9], [10].

Using AM technologies, the model is created by gradual application of layers of material in the form of strings, powder, resin or plates [11], [12], [13]. It follows that the thickness of the layer of applied material is one of the limiting factors that fundamentally affect the final surface quality of the wax model. As has been shown previously, for example in the context of metallic 3D printing, by reducing the thickness of the layers of applied material, it is possible to achieve a lower surface roughness of the component to be formed [14]. However, the thickness of the layer is not the only limiting factor that affects the final quality of the model. 
Other parameters that can fundamentally affect its quality include, for example, the speed of movement of the AM equipment components, temperatures used to process the polymer material, set trajectories and the methodology of creating individual layers of the model and the associated orientation of the model in space on the AM construction site. In addition to the above, the quality of the model is also related to the quality of the input semi-finished products, which are usually processed with different qualities [15], [16], [17]. Fig. 7 shows the surface structure quality of the polymer models formed from three different materials using three different AM technologies.
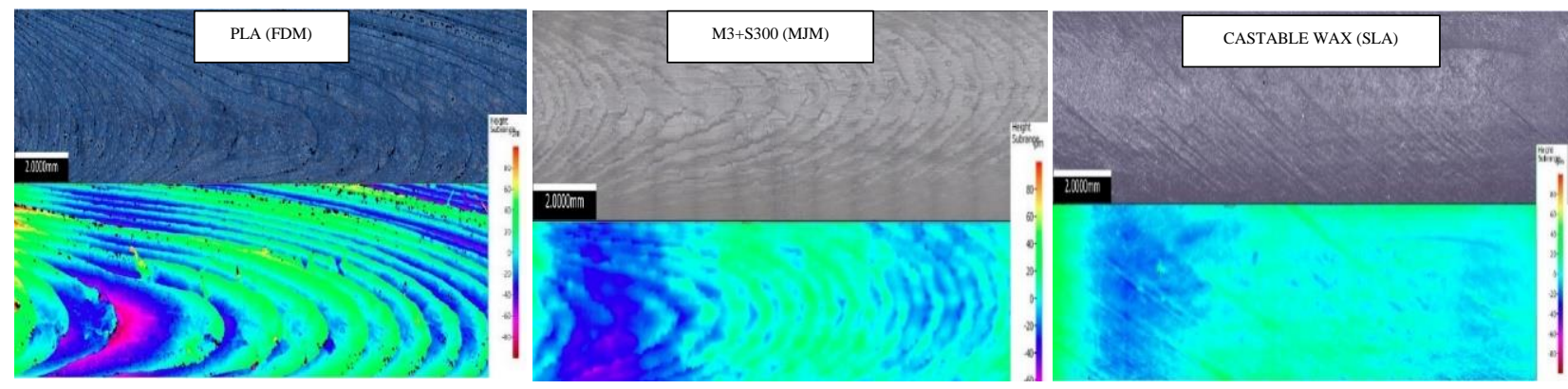

Fig. 7. Comparison of surface topography of polymer models created using FDM, MJM and SLA technology.

From this comparison (Fig. 7), it is evident that the greatest height differences between the model surfaces were recorded on the models from the FDM printer, even when the height of the applied layer of the material changed. When using other AM techniques, the differences in height between the individual surfaces of the model were smaller, also due to the fact that the models were printed in different positions than in the case of printing on FDM printers. An example of the effect of model orientation on model quality is shown above in Figure 7, where a model printed using SLA technology was otherwise oriented to the building plate and thus had the lowest variance in the heights of the surfaces of which the model consists compared to other models.

The final quality of the wax model and subsequently the casting is also affected by the shape of the casting. With complex shapes, depending on the AM technology, their roughness and structure differ on different surfaces, which is evident from the surface topography measurement above, see Fig. 7.

Below, see Figures 8-9, the measured differences in roughness between the formed polymer models and the castings are recorded. The measured values for the castings are further compared with the values measured for the casting obtained by the conventional IC route. The measured data was compared from the point of view of two basic parameters for the subsequent processing of the musical instrument keys. The first parameter was the change in the roughness $\mathrm{Rz}$ and $\mathrm{Ra}$, respectively, see Fig. 8. The change in these two parameters indicates the overall roughening, or a reduction in the roughness of the casting compared to the model. The second parameter compared was the change in the area of the grooves presented by the parameters Mr2 and Rvk, see Fig. 9.

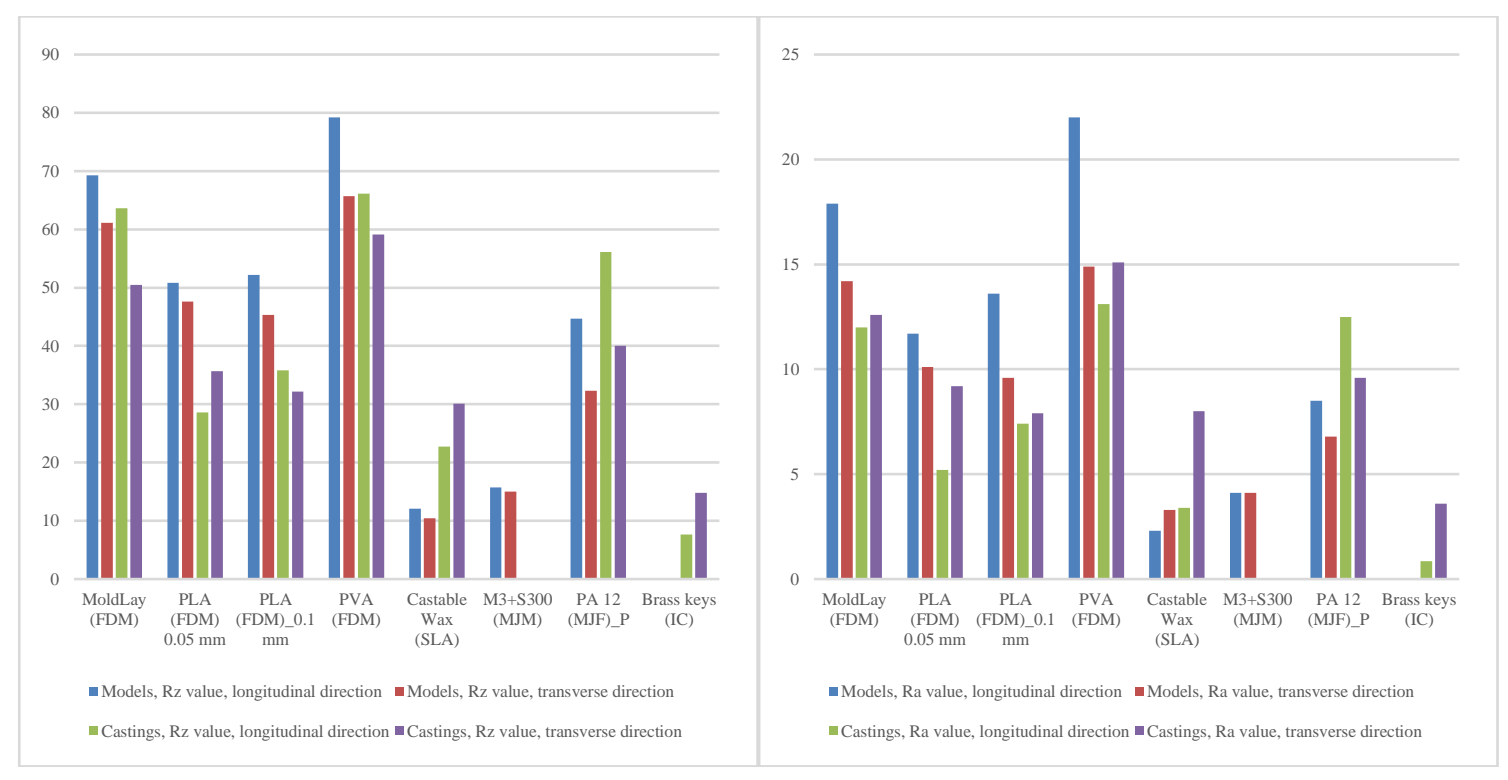

Fig. 8. Comparison of roughness on models and castings obtained by additive technologies FDM, MJM, MJF and SLA, with surface roughness of a casting which was produced using conventional IC technology 
As can be seen from the values in the graphs above (Fig. 8), it can be said that for castings using models created by FDM printers, there was a paradoxical reduction in surface roughness. This results from the fact that the individual layers are visible on the models, which the moulding mixture could not wet completely and so it was not possible to fill them down to the smallest detail. In the case of models obtained from all other AM devices, there is an increase in roughness, however, this is to some extent influenced by the occurrence of defects on the measured lengths. Unfortunately, no data are available for the casting obtained from the master from the MJM printer, as the mould cracked and the cast alloy was spilled during firing. The cracking of the mould was probably due to large differences in the coefficients of thermal expansion between the mould material and the polymer model. The fact that the model was created in full contributed to the fact that the form was broken. As mentioned in some studies, when making these models from polymeric materials, it is advantageous to make them hollow, because then they collapse before the mould breaks [18]. When comparing the achieved roughness on castings and respectively also models obtained by AM technologies, it is evident that when using a conventional method of material processing, the surface roughness of the casting is significantly lower in both measured directions.

For further machining of the casting, it is important that the area of the grooves on its surface is as low as possible. Below is the formula (1) used for calculating the area of grooves, which is based on the shape of the so-called Abbot curve. This formula is based on the assumption that the area of the grooves is in the shape of a right triangle.

$$
\text { Grooves area }=\frac{\left(\left(100-M_{r 2}\right) \cdot R_{v k}\right)}{2}\left[\mu m^{2}\right]
$$

A comparison of the change in the parameters of Mr2, Rvk and the calculated change in the area of grooves in polymer models and subsequently formed castings is given below, see Fig. 9. The results are compared with the values measured on the surface of a casting produced by conventional IC.

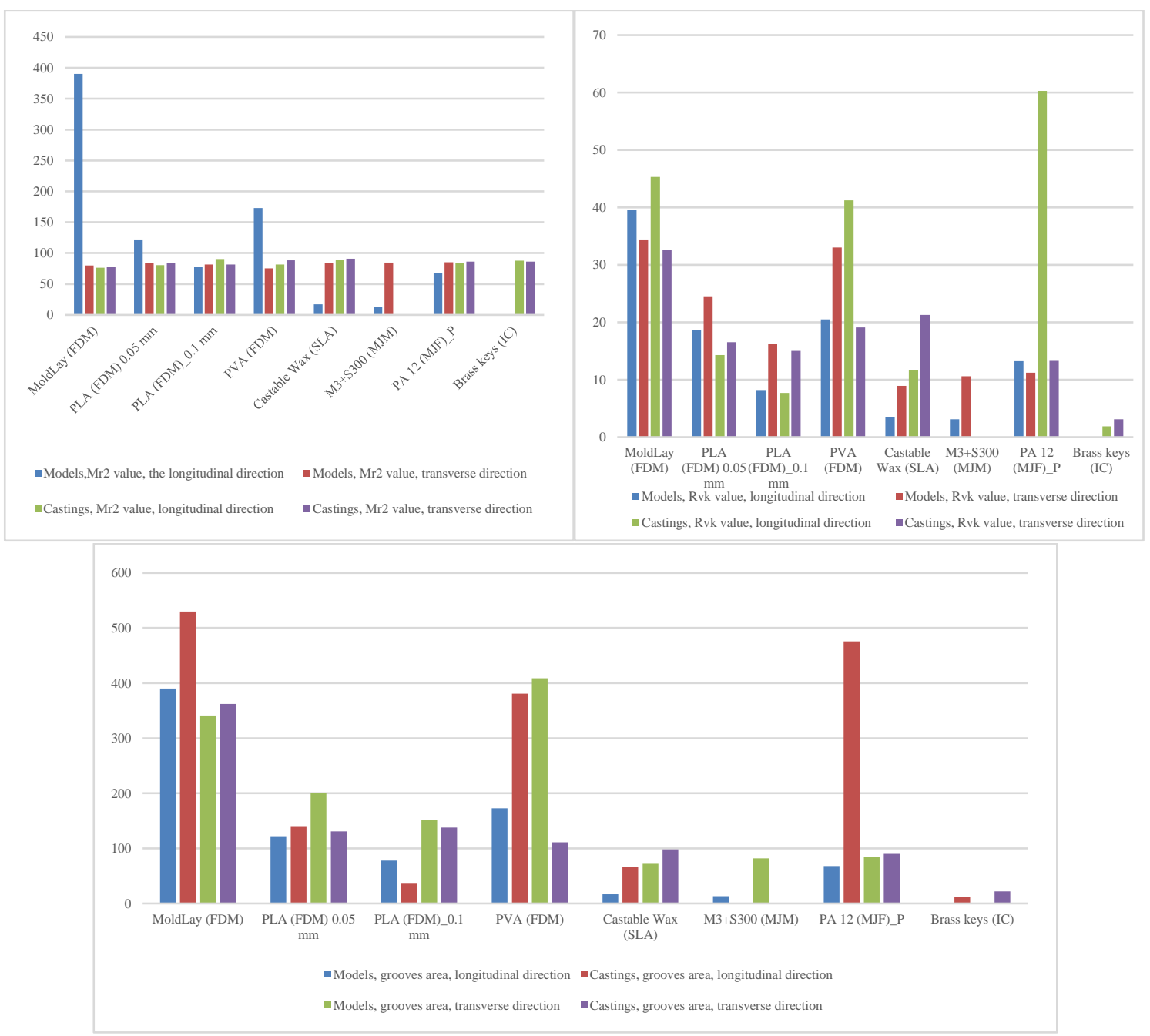

Fig. 9. Comparison of the proportion of material below the roughness profile Mr2 and reduced depth of grooves Rvk on models and castings obtained by additive technologies FDM, MJM, MJF and SLA, with the values of the surface of the casting, which was produced using conventional IC technology 
From the comparison of parameters above (Fig. 9), it follows that the conventionally produced casting has a significantly lower area of grooves on its surface in both measured directions, not only with respect to the castings, but also the polymer models obtained using various AM techniques. With these models, it is evident that the area of the grooves differs in the different directions of measurement. This is connected with the method of layering the material and the thickness of the formed layers of material during their processing.

\subsection{Surface defects of castings}

The surface quality of castings obtained after moulding polymer models produced on AM equipment was, in addition to the technology of their processing, influenced by the method of their moulding. Below, see Fig. 10, some of the defects associated with this process are noted.

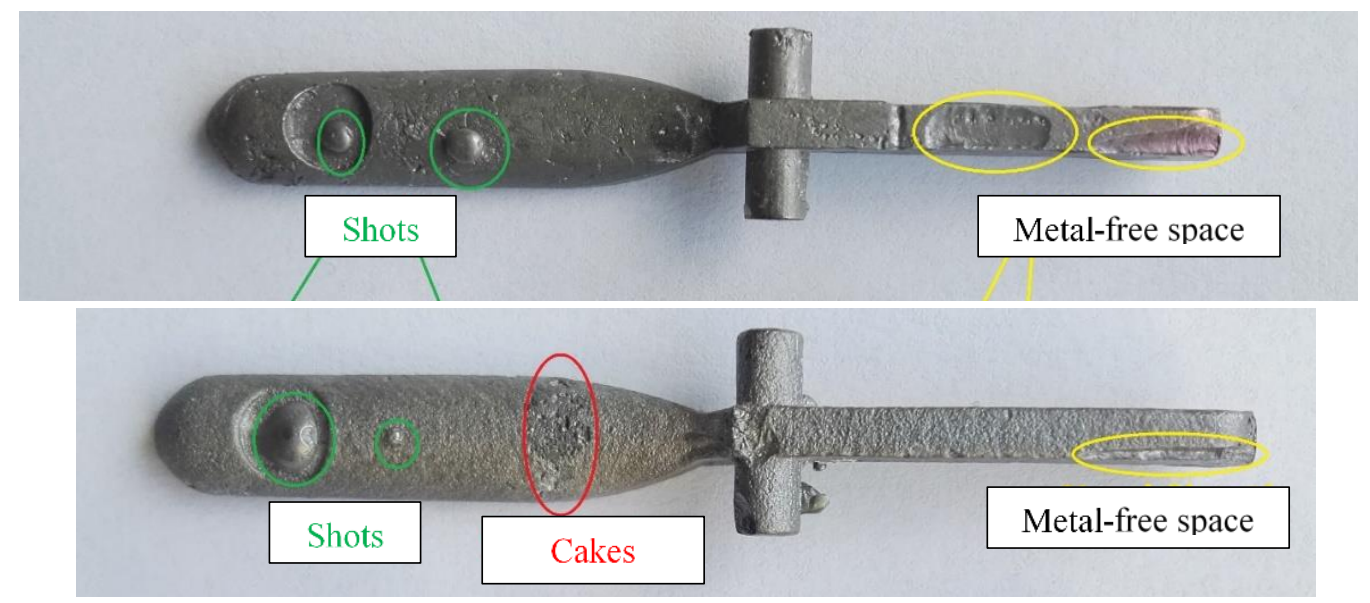

Fig. 10. Examples of defects recorded on the surfaces of castings which were created by casting a tin alloy. The upper image shows a casting in which the wax model was created by SLA technology on the Original Prusa SL1 printer, made of CastableWax material. The lower image shows a casting in which the wax model was created by MJF technology on an HP Jet Fusion 4200 printer, made of PA12 material

During the production of the gypsum mould, into which the metal was subsequently cast, air bubbles were formed. These bubbles remained trapped on the polymer models surfaces. After the mould had been fired, unfilled areas remained in these places. After firing the mould and casting the material, these areas were then filled with liquid metal, which after solidification formed defects on the surface of the casting known as shots, see Fig. 10 above. In addition to this defect, cakes were observed on the surface of the castings. This type of defect is caused by the disruption of the mould interface by molten metal. This can occur, for example, due to poor firing of the mould, when the mould does not have sufficient rigidity, or due to dissolution of the mould by molten metal. These defects usually occur at large interfaces, where molten metal can act on the mould interface for a sufficiently long time. In the case of this study of formed castings, the ash which remained trapped inside the mould after firing probably also contributed to the formation of cakes.

In the case of some castings, the metal alloy did not run into some areas of the casting. This was probably due to the impaired deposition capacity of the metal in these areas. Here, it was probably due to the fact that the supply channel solidified earlier and so the settling capacity of the metal was not sufficient.

\section{Conclusion}

The aim of this study was to analyse the applicability of AM technologies in the process of casting on a fusible model. Their use should reduce the production times required to complete the castings. The applicability of AM technologies was studied for their use in the production of wax models.

The results of the above analyses can be summarized as follows:

- The polymer materials used in AM equipment showed a higher proportion of non-combustible components compared to the Flexible Blue material, which is commonly used to produce fusible models in IC technology.

- A higher proportion of ash was also recorded in the case of materials or waxes intended directly for the creation of fusible models using additive technologies. In the case of Castable Wax material processed on an SLA type printer, the ash content was higher by approximately $120 \%$. In the case of MouldLay material processed on an FDM type printer, their share was higher by about $870 \%$.

$\circ$ The highest proportion of ash was recorded for PA12 material processed on an MJF type printer. The amount of flue gas in the case of this material was higher by about $1100 \%$ 
- The lowest proportion of ash in materials processed on AM equipment was shown by the combination of materials $\mathrm{M} 3+\mathrm{S} 300$, processed on the printer type MJM and material PVA processed on the printer type FDM. In the case of the combination of materials M3 + S300, the share of ash was higher by about $25 \%$ and in the case of PVA material, by about $70 \%$.

- The surface topography of the created polymer models differed for different samples depending on the construction strategy of the polymer model production and the possibilities of using AM devices.

$\circ \quad$ The greatest height differences between the surfaces (protrusions) of the wax model were recorded for models created on FDM type printers. Significantly smaller differences were recorded for models created using MJM and SLA technologies.

- By measuring the roughness in different areas on the polymer models and subsequently the castings, it was found that the roughness and the total area of the grooves is significantly lower in castings obtained using the conventional IC method.

- Castings modelled on FDM printers have a lower surface roughness than polymer models. In contrast, castings obtained using other AM techniques showed an increase in roughness.

- The largest area of grooves was recorded in castings based on polymer models made of Mouldlay material processed by an FDM type printer and PA12 material processed by an MJF type printer. For these materials, the area of the grooves reached, in the case of the Mouldlay material, depending on the measuring direction, values of $530 \mu \mathrm{m} 2$ in the longitudinal measuring direction and $362 \mu \mathrm{m} 2$ in the transverse direction. For the PA12 material, the area of the grooves reached a value of $476 \mu \mathrm{m} 2$ in the longitudinal direction.

- The smallest area of grooves was recorded for castings modelled on polymer models made of Castable Wax material processed by an SLA type printer, in which the area of grooves was $67 \mu \mathrm{m} 2$ in the longitudinal direction and $98 \mu \mathrm{m} 2$ in the perpendicular direction. However, this value is still higher than the area of the grooves calculated on the area of a casting produced using the conventional method, where their value reaches $11 \mu \mathrm{m} 2$ in the longitudinal direction and $22 \mu \mathrm{m} 2$ in the perpendicular direction.

From the above data, we can state that the complexity of further machining of castings based on models created on various AM devices, would be higher compared to the conventional production method. The reason is that their surface is formed by a higher proportion of grooves, which increase the demands on its further processing. A change in the way the polymer models are formed could help to increase the quality of the castings, for example by using a vacuum which would help to remove air bubbles from the volume of the moulding material. Because a large number of keys of various shapes are required to fit the musical instrument, it is increasingly advantageous to use a standard production path for their production. However, additive technology could be applied to the production of the parent models that are used to make the moulds for the production of the polymer models analysed in this study. Further research will deal with optimizing the shape of these parent models and optimizing the parameters of their production by appropriate AM techniques, which will be selected based on the results presented here.

\section{Acknowledgment}

This article was made possible by the funding for the SGS-2018-051 project "Application of new treatment and test procedures to surfaces and bulk materials for improved usability of assemblies and work tools in industry"

\section{References}

[1] Horáček, M. (2009). Rozměrová přesnost odlitků vyráběných metodou vytavitelného modelu, Available from: http: http://ust.fme.vutbr.cz/slevarenstvi/sites/default/files/clanky/technologie-vytavitelneho-modelu/technologievytavitelneho-modelu.pdf Accessed: 2020-07-01

[2] Beeley, P. R. \& Smart, R. F. (1995). Investment Casting, . Institute of Materials, ISBN 0901716669, London.

[3] Bricín, D. (2014). The Design of Copper Alloy for the Castings of Musical Instruments. Master thesis. Department of material science and technology, University of West Bohemia, Pilsen, Czech Republic

[4] Cheah, C.M.; Chua, C.K.; Lee, C.W.; Feng, C. \& Totong, K. (2005). Rapid prototyping and tooling techniques: a review of applications for rapid investment casting. The International Journal of Advanced Manufacturing Technology. ISSN 0268-3768. DOI: 10.1007/s00170-003-1840-6

[5] CSN EN ISO 4287. (1999). Geometrical Product Specifications (GPS) - Surface texture: Profile method — Terms, definitions and surface texture parameters. Czech office for standards, metrology and testing

[6] CSN EN ISO 16610-21. (2012). Geometrical product specifications (GPS) - Filtration - part 21: Linear profile filters: Gaussian filters. Czech office for standards, metrology and testing

[7] CSN 42 1240. (1965). Castings Defects. Terminology and Classification of Defects. Czech office for standards, metrology and testing

[8] Pielichowski, K. \& Njuguna, J. (2005). Thermal Degradation Of Polymeric Materials, Smithers Rapra Press, ISBN: 9781859574980, Shawbury. 
[9] Bonilla, W.; Masood, S. \& Iovenitti, P. (2001). An Investigation of Wax Patterns for Accuracy Improvement in Investment Cast Parts. The International Journal of Advanced Manufacturing Technology, Vol. 18, No. 5, pp. 348356. DOI: 10.1007/s001700170058

[10] Luca, A. I.; Balc, N. O.; Popan, I. A. \& PANC, N. (2010). Dimensional accuracy analysis in casting using easily fusible models. Proceedings of the 21st International DAAAM Symposium, Vol. 21, No. 1. ISSN 1726-9679.

[11] Prakash, K.; Nancharaih, T. \& Rao, V. (2018). Additive Manufacturing Techniques in Manufacturing -An Overview. Materials Today: Proceedings, Vol. 5, No. 2, pp. 3873-3882. DOI: 10.1016/j.matpr.2017.11.642

[12] Gibson, I.; Rosen, D. \& Stucker, B. (2015). Additive Manufacturing Technologies, Springer, ISBN: 978-1-49392112-6, New York

[13] Baier, O. \& Witt, G. (2011). Electroplating of AM wax models for the production of internal structures. Proceedings of the 22nd International DAAAM Symposium, Vol. 22, No. 1, ISSN 1726-9679

[14] Kovan, V.; Altan, G. \& Topal, E. (2017). Effect of layer thickness and print orientation on strength of 3D printed and adhesively bonded single lap joints. Journal of Mechanical Science and Technology, Vol. 31, No. 5, pp.21972201. DOI: 10.1007/s12206-017-0415-7.

[15] Zetkova, I.; Kucerova, L.; Zetek, M.; Cesanek, J.; Hanzl, P. \& Dana, M. (2017). Evaluation of Metal Powder for Additive Manufacturing of Margaring Steel. Proceedings of the 28th International DAAAM Symposium, Vol. 28, No. 1, pp. 0410-0416. ISSN 1726-9679. DOI: 10.2507/28th.daaam.proceedings.057.

[16] Bricín, D. \& Kříž, A. Assessment of usability of WC-Co powder mixtures for SLM. (2018). Manufacturing Technology, Vol. 18, No.5, pp.719-726. ISSN 1213-2489.DOI:10.21062/ujep/166.2018/a/1213-489/MT/18/5/719

[17] Ligon, S.; Liska, R.; Stampfl, J.; Gurr, M. \& Mülhaupt, R. (2017). Polymers for 3D Printing and Customized Additive Manufacturing. Chemical Reviews, Vol. 117, No. 15, pp. 10212-10290. DOI: 10.1021/acs.chemrev.7b00074

[18] Harun, W.; Sharif, S.; Idris, M. \& Kadirgama, K.; (2009). Characteristic studies of collapsibility of ABS patterns produced from FDM for investment casting. Materials Research Innovations, Vol. 13, No. 3, pp. 340-343. DOI: https://doi.org/10.1179/143307509X441513 